\begin{tabular}{|ll|}
\hline Received & $:$ 26 Februari 2020 \\
Revised & $:$ 30 Maret 2020 \\
Accepted & $:$ 20 April 2020 \\
Online & $:$ 25 April 2020 \\
Published & $:$ 30 April 2020 \\
\hline
\end{tabular}

\title{
Implementasi Internet of Things (IoT) untuk Meningkatkan Kompetensi Siswa SMK Jakarta 1
}

\author{
Ahmad Fitra Ritonga $^{1, a)}$, Syafrima Wahyu ${ }^{1}$, Frida Octavia Purnomo ${ }^{1}$ \\ ${ }^{1}$ Program Studi Teknik Fisika, Universitas Binawan \\ $\varangle$ : ${ }^{a}$ fitra@binawan.ac.id
}

\begin{abstract}
Internet of Things (IoT) needs to be developed in education and serves as one of the roles of education to face the industrial revolution 4.0. Vocational High School (SMK) is an appropriate level of education to prepare early for knowledge and application of IoT technology. Vocational High School Jakarta 1 has good technology but the competency of applying IoT expertise is still lacking. To improve the understanding and application of IoT, Physics Engineering Study Program of Binawan University proposes a solution in the form of training with the theme: Implementing Internet of Things (IoT) to improve student competence in Vocational High School Jakarta 1. This training aims to introduce about IoT especially implementation in the scheme monitoring by using light and temperature sensors to increase student motivation and competence in the industrial era 4.0. Based on the analysis of the data, it was concluded that the competency of student expertise could be significantly increased through IoT training to be accepted with significance level of 0.05. The method of implementing training is team work that is able to make the training more effectively and efficiently.
\end{abstract}

Keywords: Training, Education, IoT

\begin{abstract}
Abstrak
Internet of Things (IoT) perlu dikembangkan di dunia pendidikan dan dijadikan sebagai salah satu peran pendidikan untuk menghadapi revolusi industri 4.0. Sekolah Menengah Kejuruan (SMK) merupakan jenjang pendidikan yang tepat untuk mempersiapkan lebih awal terkait pengetahuan dan penerapan teknologi IoT. SMK Jakarta 1 mempunyai teknologi yang baik namun kompetensi keahlian pengaplikasian IoT dinilai masih kurang. Untuk meningkatkan pemahaman dan aplikasi IoT, program studi Teknik Fisika Universitas Binawan mengusulkan sebuah solusi dalam bentuk pelatihan dengan tema Implementasi Internet of Things (IoT) untuk meningkatkan kompetensi siswa di SMK Jakarta 1. Pelatihan ini bertujuan untuk mengenalkan kepada siswa tentang IoT khususnya implementasi dalam skema monitoring dengan menggunakan sensor cahaya dan temperatur untuk meningkatkan motivasi serta kompetensi siswa di era industri 4.0. Berdasarkan analisis data diperoleh kesimpulan bahwa kompetensi keahlian siswa dapat ditingkatkan secara signifikan melalui pelatihan IoT dapat diterima pada tingkat signifikansi 0.05. Metode pelaksanaan pelatihan berbentuk kerja kelompok yang mampu membuat pelatihan berlangsung secara efektif dan efisien.
\end{abstract}

Kata-kata kunci: Pelatihan, Pendidikan, IoT

\section{PENDAHULUAN}

Internet of Things (IoT) adalah arsitektur sistem yang terdiri dari perangkat keras, perangkat lunak, dan web, karena perbedaan protokol antara perangkat keras dengan protokol web, maka diperlukan sistem embedded berupa gateway untuk menghubungkan dan menjembatani perbedan protokol tersebut (Prihatmoko, 2016). Tujuannya adalah untuk membuat manusia lebih mudah berinteraksi dan dinama semua mesin dengan pengenal IP address dapat menggunakan jaringan 
internet sebagai media komunikasi (Efendi, 2018). Piranti penting dalam pelatihan ini adalah Arduino. Menurut Maulana (2014), arduino adalah pengendali mikro single-board yang bersifat open-source, diturunkan dari wiring platform, dirancang untuk memudahkan penggunaan elektronik dalam berbagai bidang. Herfiansyah (2014) menjelaskan bahwa kompleks perancangan dan program yang dibuat harus sesuai dengan jenis kontroler yang digunakan. Jadi yang membedakan antara arduino yang satu dengan yang lainnya adalah penambahan fungsi dalam setiap papan circuitnya dan jenis mikrokontroler yang digunakan. (Aditya, 2015).

Internet of Things dalam penerapannya juga dapat mengidentifikasi, menemukan, melacak, memantau objek dan memicu event terkait secara otomatis dan real time, Pengembangan dan penerapan komputer, Internet dan teknologi informasi dan komunikasi lainnya (TIK) membawa dampak yang besar pada masyarakat manajemen ekonomi, operasi produksi, sosial manajemen dan bahkan kehidupan pribadi (Junaidi, 2015).

Pemerintah telah mempersiapkan diri dalam menghadapi revolusi ini. Pemerintah tengah mengembangkan teknologi IoT untuk mendukung penerapan konsep Smart City (Santyadiputra et. al, 2017). Selain itu, pemerintah dengan dinas pendidikan juga sedang mengembangkan pola pendidikan yang mendukung paradigm dan implementasi dari revolusi industri 4.0. Implementasi tersebut tersebut dapat dikembangkan melalui kurikulum yang mampu menghasilkan generasi muda yang kompoten di bidang teknologi dengan mengedepankan kemampuan inovasi dan kreativitas teknologi.

Sekolah Menengah Kejuruan (SMK) adalah sasaran yang tepat untuk mempersiapkan lebih awal terkait pengetahuan teknologi IoT. SMK pada umumnya dipersipakan memiliki kemampuan lebih dibidang teknologi. Penelitian sebelumnya menunjukkan media pembelajaran rumah pintar berbasis IoT (Internet of Things) beserta jobsheet ini layak digunakan sebagai alat bantu siswa untuk praktikum agar meningkatkan hasil belajar dalam ranah psikomotor atau hasil kinerja (Afrizal, 2018). Oleh sebab itu sangat perlu diterapkan pemahaman dan aplikasi IoT di dunia pendidikan khususnya jenjang pendidikan kejuruan.

Berdasarkan hasil wawancara tim dengan guru dan juga siswa SMK Jakarta 1. Hasil wawancara menggambarkan bahwa guru mata pelajaran teknologi dan informasi sudah memberikan sepenuhnya pengetahuan dan dasar teknologi internet, namun belum semuanya diimplementasikan dalam pembelajaran. Begitu juga dengan pendapat beberapa siswa yang mengungkapan bahwa pengetahuan teknologi internet di sekolah sudah baik, namun penerapan teknologi yang masih kurang sehingga dampaknya kemampuan teknologi siswa tidak begitu berkembang.

Kepala sekolah berharap kedepannya SMK Jakarta 1 akan ikut serta dan berperan dalam pengembangan internet dan teknologi yang sehingga lulusan mampu bersaing dan dapat diterima ditempat kerja yang diinginkannya. Oleh karena sebab itu, dalam rangka untuk memenuhi kebutuhan keilmuan siswa terhadap IoT dan untuk meningkatkan motivasi serta kompetensi siswa, maka program studi Teknik Fisika Universitas Binawan berinisiatif mengadakan penelitian mengenai "Implementasi Internet of Things (IoT) untuk Meningkatkan Kompetensi Siswa di SMK Jakarta 1".

\section{METODE}

Pelaksanaan kegiatan penelitian dirancang berdasarkan pada kerangka pemecahan masalah. Kerangka pemecahan masalah mengenai pemahaman IoT dibentuk dalam suatu pelatihan (Santyadiputra et. al, 2017). Kerangka tersebut diperbaharui sesuai dengan perencanaan tim. Kerangka pemecahan masalah dapat dilihat pada Gambar 1. 


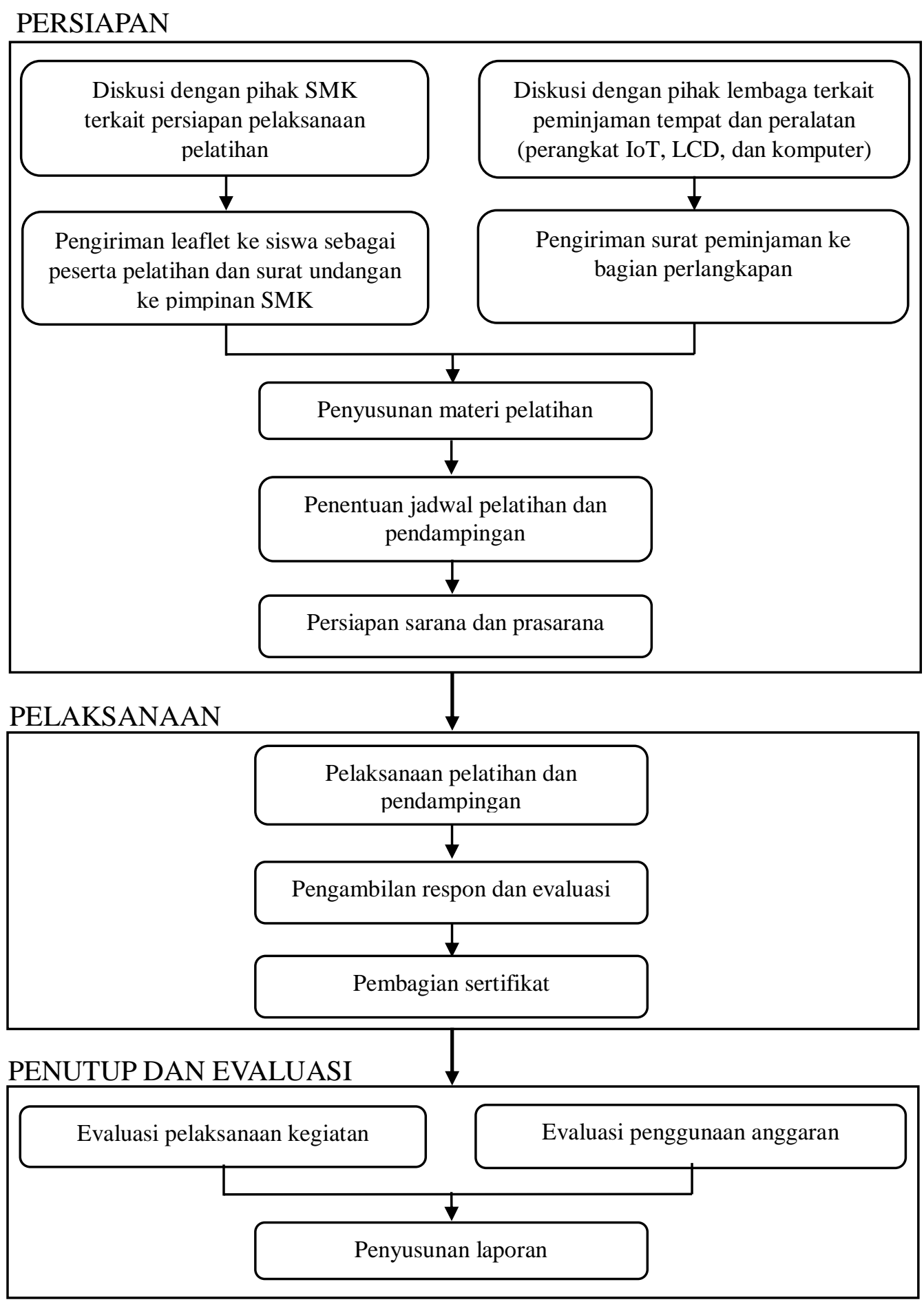

GAMBAR 1. Kerangka Pemecahan Masalah

Kerangka di atas dijadikan sebagai acuan dalam pelaksanaan kegiatan implementasi IoT dalam bentuk pelatihan. Secara umum, kerangka tersebut dibagi menjadi 3 tahap yaitu persiapan, pelaksanaan, dan penutup \& evaluasi. Pada tahap persiapan dilakukan diskusi ke pihak-pihak terkait masalah perijinan meliputi perijinan ke pihak SMK sebagai penyelenggaran sekaligus tempat diadakannya pelatihan dan ke pihak mitra terkait narasumber, peminjaman perangkat IoT, dan sebagainya. Tahap ini juga menjadi acuan persiapan bahwa peserta, peralatan, materi, dan tempatnya tersedia. Kemudian dilakukan pengiriman surat pernyataan kesediaan kerjasama secara formal ke 
pihak SMK maupun mitra. Tahap selanjutnya adalah pelaksanaan pelatihan. Pelatihan dilakukan dalam $1 \mathrm{x}$ pertemuan. Pada saat akhir pelatihan dikumpulkan respon terkait pelaksanaan pelatihan kepada peserta. Tahap akhir berupa evaluasi terhadap pelaksanaan pelatihan serta penggunaan dana yang diakhiri dengan penyusunan laporan akhir.

Metode yang diterapkan dalam pelaksanaan kegiatan ini adalah pelatihan kerja kelompok. Siswa akan diberikan materi awal berupa pengenalan teknologi IoT dan perangkat-perangkat pendukungnya serta pengimplementasian IoT ke sebuah skema monitoring dengan menggunakan sensor cahaya dan suhu. Setelah itu, diberikan sebuah kasus yangmana solusinya adalah membuat rangkaian alat dengan mengikuti skema monitoring tersebut.

Mekanisme dan langkah-langkah pengerjaan dibuat dalam bentuk modul pemrograman yang ditampilkan saat presentasi. Di akhir kegiatan peserta diminta kesediaannya untuk mengisi angket respon sebagai evaluasi kegiatan pelatihan dan peserta akan diberikan souvenir dijadikan sebagai sebagai ucapan terimakasih atas terlaksananya kegiatan pelatihan.

Evaluasi pelatihan terbagi dua yaitu evaluasi selama kegiatan berlangsung dan evaluasi pemahaman siswa tentang IoT. Evaluasi kegiatan pelatihan diberikan setelah pelatihan berakhir dalam bentuk pertanyaan-pertanyaan terkait pelaksanaan pelatihan berlangsung sedangkan evaluasi pemahaman siswa tentang IoT dilaksanakan sebelum dan sesudah pelatihan. Evaluasi pemahaman siswa berbentuk tes tertulis dalam bentuk soal pilihan ganda. Soal tersebut disusun dalam dua bentuk format yaitu soal pre-test dan postest. Pre-test dilaksanakan sebelum pelatihan sedangkan post-test dilaksanakan setelah pelaksanaan pelatihan dan simulasi. Nilai yang diperoleh oleh siswa diolah dengan cara membandingkan persentase keberhasilan siswa sebelum dan sesudah pelatihan.

\section{HASIL DAN PEMBAHASAN}

Penelitian dilaksanan mulai pada awal Februari sampai akhir Mei di SMK Jakarta 1. Masalah yang dihadapi oleh siswa SMK Jakarta adalah kurangnya kompetensi keahlian siswa dalam menghadapi Revolusi Industri 4.0. Untuk mengatasi permasalah tersebut, maka dosen-dosen program studi Teknik Fisika melaksanakan pelatihan dengan tema implementasi IoT ke sebuah skema monitoring dengan menggunakan sensor cahaya dan suhu. Pelatihan ini bertujuan untuk meningkatkan dan menemukan pola latihan kerja kelompok yang efektif untuk meningkatkan kompetesi keahlian siswa.

Hasil yang diperoleh dari penelitian ini berupa data pretest dan postest. Pengambilan data pretest dan postest dibantu dengan aplikasi Quizizz sehingga diperoleh data real dan bisa didownload berupa data exel. Data pretest merupakan data sebelum dilaksanan presentasi pelatihan sedangkan data postest merupakan data yang diperoleh setelah dilaksanakan presentasi dan pelatihan. Deskripsi data hasil penelitian tersebut akan dijelaskan berikut ini.

Deskripsi data merupakan suatu cara untuk menyajikan data hasil penelitian dengan jelas dengan tujuan agar dapat dipahami dan dianalisis. Deskripsi data pada penelitan ini mencakup deskripsi data pretest dan postest. Teknik yang digunakan adalah teknik tes tertulis dalam bentuk soal pilihan ganda sebanyak sepuluh buah soal. Soal ini diberikan kepada siswa pada sebelum dan sesudah kegiatan pelatihan.

Analisis data adalah upaya mengolah data menjadi informasi, sehingga karakteristik atau sifatsifat data tersebut dapat dengan mudah. Analisis data pada penelitian ini adalah analisis data pretest dan postest. Data pretest dan postes ttersebut dianalisis sehingga menjadi informasi yang dapat diinterpretasikan dan dimaknai. Sebelum melakukan uji statistik, terlebih dahulu dilakukan uji normalitas dan homogenitas terhadap data pretest dan postest. Kemudian dilakukan uji kesamaan dua rata-rata dengan menggunakan uji statistik yang sesuai.

Uji normalitas merupakan salah satu bagian dari uji persyaratan analisis data atau uji asumsi klasik, artinya sebelum melakukan analisis statistik untuk uji hipotesis dalam hal ini adalah analisis regresi pada taraf nyata 0,05 . Uji normalitas pada penelitian ini menggunakan Uji Normalitas Kolmogorov-Smirnov. Dasar pengambilan keputusan dalam uji normalitas K-S: (1) Jika nilai signifikansi (Sig.) lebih besar dari 0.05 maka data berdistribusi normal. (2) Sebaliknya, jika nilai signifikansi (Sig.) lebih kecil dari 0,05 maka data tidak berdistribusi normal. Hasil perhitungan uji normalitas K-S dengan menggunakan SPSS diuraikan pada Tabel 1 berikut. 
TABEL 1. One-sample kolmogorov-smirnov test

\begin{tabular}{|c|c|c|}
\hline $\mathbf{N}$ & Unstandardize & Residual \\
\hline \multirow{2}{*}{ Normal Parameters ${ }^{a, b}$} & Mean & 0.000000 \\
\hline & Std. Deviation & 20.77750085 \\
\hline \multirow{3}{*}{$\begin{array}{l}\text { Most Extrime } \\
\text { Differences }\end{array}$} & Absolute & 0.110 \\
\hline & Positive & 0.067 \\
\hline & Negative & -0.110 \\
\hline Test Statistic & & 0.110 \\
\hline Asymp. Sig. (2-tailed) & & $0.191^{\mathrm{c}}$ \\
\hline
\end{tabular}

Berdasarkan Tabel 1 hasil SPPS tersebut menunjukkan bahwa nilai signifikansi Asiymp.Sig (2tailed) sebesar 0,191 lebih besar dari 0,05. Maka sesuai dengan dasar pemgambilan keputusan dalam uji normalitas Kolmogorov-Smirnov di atas, dapat disimpulkan bahwa data berdistribusi normal.

Uji homogenitas dilakukan untuk mengetahui apakah kedua sampel homogen atau tidak. Uji homogenitas merupakan hasil perbandingan nilai varians dari dua sampel. Dasar atau pedoman pengambilan keputusan dalam uji homogenitas adalah sebagai berikut. (1) Jika nilai signifikansi (Sig.) $<0.005$, maka dikatakan bahwa varians dari dua atau lebih kelompok populasi data adalah tidak sama (tidak homogen). (2) Jika nilai signifikansi (Sig.) $>0.005$, maka dikatakan bahwa varians dari dua atau lebih kelompok populasi data adalah sama (homogen). Hasil perhitungan uji homogenitas dengan menggunakan SPSS diuraikan pada Tabel 2 berikut.

Tabel 2. Test of Homogenity of Variances

\begin{tabular}{|c|c|c|c|c|c|}
\hline & & Levene Statistic & $d f 1$ & $d f 2$ & Sig. \\
\hline \multirow{4}{*}{$\begin{array}{l}\text { Hasil } \\
\text { kompetensi } \\
\text { Keahlian }\end{array}$} & Based on Mean & 3.251 & 1 & 94 & 0.075 \\
\hline & $\begin{array}{l}\text { Based on } \\
\text { Median }\end{array}$ & 1.953 & 1 & 94 & 0.166 \\
\hline & $\begin{array}{l}\text { Based on } \\
\text { Median and with } \\
\text { adjusted df }\end{array}$ & 1.953 & 1 & 76.574 & 0.166 \\
\hline & $\begin{array}{l}\text { Based on } \\
\text { trimmed mean }\end{array}$ & 2.889 & 1 & 94 & 0.092 \\
\hline
\end{tabular}

Berdasarkan Tabel 2 di atas menunjukkan nilai signifikansi Based on Mean untuk variabel hasil kompetensi keahlian adalah sebesar 0.075, karena nilai $0.075>0.05$, maka dapat disimpulkan bahwa varians data hasil kompetensi keahlian siswa berupa pretest dan postest adalah homogen.

Uji hipotesis yang digunakan adalah uji kesamaan dua rata-rata atau uji z. Uji z digunakan untuk menguji hipotesis koperasional. Untuk kepentingan pengujian hipotesis dengan menggunakan statistika maka hipotesis yang tertera di atas dirumuskan ke dalam hipotesis operasional sebagai berikut: "Ada perbedaan antara nilai rata-rata kompetensi keahlian siswa sebelum dilakukan pelatihan dengan nilai rata-rata kompetensi keahlian siswa sesudah dilakukan pelatihan". Ini disebut hipotesis kerja $\left(\mathrm{H}_{1} /\right.$ Hipotesis Alternatif). Selanjutnya untuk menggunakan teknik statistika untuk menguji hipotesis kerja (apakah dapat diterima atau ditolak), maka hipotesis ini harus diubah lebih dahulu menjadi hipotesis nol $\left(\mathrm{H}_{0}\right)$ yaitu:"Tidak ada perbedaan antara nilai rata-rata kompetensi keahlian siswa sebelum dilakukan pelatihan dengan nilai rata-rata kompetensi keahlian siswa sesudah dilakukan pelatihan". Jika dari hasil pengujian ternyata hipotesis nol ditolak, maka hipotesis alternatif $\left(\mathrm{H}_{1}\right)$ yang merupakan hipotesis kerja diterima. 
Kriteria pengujian data terdiri dari dua macam yaitu uji data berdasarkan nilai $\mathrm{z}$ atau uji data berdasarkan nilai probabilitas. Kriteria uji data yang dilakukan adalah berdasarkan nilai z dengan pernyataaan: tolak $\mathrm{H}_{0}$, jika nilai z hitung lebih besar dari nilai z daftar. Selanjutnya dilakukan analisis data dengan cara mempersiapkan data terlebih dahulu. File data yang akan dianalisis berupa data pretest dan postest berbentuk kolom untuk menguji kompetensi keahlian siswa sebelum dan sesudah dilakukan pelatihan. Analisis data tersebut dilakukan pada program Exel pada menu Data kemudian diklik Data Analysis. Analysis tool yang digunakan adalah z-Test:Two Sample for Mean dengan jumlah data sebanyak 48 data. Hasil analisis data diuraikan pada Tabel 3 berikut.

TABEL 3. Z-Test: Two Sample For Means

\begin{tabular}{lll}
\hline & Pretest & Postest \\
\hline Mean & 24.79167 & 54.375 \\
Known Variance & 191.45 & 446.41 \\
Observations & 48 & 48 \\
Hypothesized Mean Difference & 0 & \\
$z$ & -8.11531 & \\
$P(Z<=z)$ one-tail & $2.22 \times 10^{-16}$ & \\
$z$ Critical one-tail & 1.644854 & \\
$P(Z<=z)$ two-tail & $4.44 \times 10^{-16}$ & \\
$z$ Critical two-tail & 1.959964 & \\
\hline
\end{tabular}

Berdasarkan Tabel 3 di atas dapat dilihat bahwa rata-rata nilai postest lebih tinggi dari rata-rata nilai pretest. Tabel di atas juga menunjukkan nilai $\mathrm{z}$ hitung dengan nilai sebesar -8.115 dan nilai $\mathrm{z}$ pada titik kritis dengan nilai sebesar 1.96 untuk taraf signifikansi 0.025 .

Pelatihan dilaksanakan pada tanggal 27 April 2019 dan dihadiri oleh 48 siswa SMK Jakarta 1 yang terdiri dari perwakilan siswa kelas X, XI, dan XII. Sebagai instruktur dalam pelatihan, hadir delegasi dari mahasiswa sebanyak 2 orang, delegasi dari NetSolution 1 orang, dan 4 orang dosen teknik fisika yang mendampingi siswa selama proses pelatihan berlangsung.

Kegiatan berlangsung di Aula SMK Jakarta 1. Pelatihan diawali dengan ujian pretest dengan menggunakan aplikasi Quizizz seperti pada Gambar 2. Siswa diwajibkan mengisi jawaban sesuai dengan pengetahuan atau pengalaman yang peserta dapatkan. Selanjutnya pengenalan teknologi IoT dengan memperhatikan penjelasan yang disampikan oleh ketua pelaksana. Setelah presentasi, siswa diarahkan untuk membentuk kelompok yang terdiri dari 4 sampai 5 orang. Dari 10 kelompok yang terbentuk, ditampilkan modul pemrograman kepada seluruh anggota kelompok. Modul pemrograman terdiri dua modul yakni modul pengukur intensitas cahaya dan modul pengukur alat pengukur suhu.

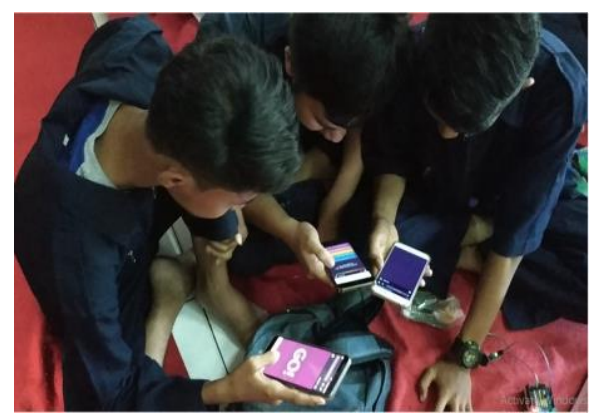

GAMBAR 2. Siswa Ujian Pretest Dan Postest

Masing-masing kelompok didampingi oleh seorang instruktur dari mahasiswa dan dosen. Tiap kelompok harus mempunyai satu komputer/laptop. Sebelum peralatan diberikan kepada siswa, siswa diarahkan terlebih dahulu menyelesaikan program dengan bantuan bimbingan instruktor seperti pada Gambar 3. Kelompok yang sudah menyelesaikan program diperbolehkan untuk mencoba 
mengkoneksikan dengan peralatan IoT seperti arduino, kabel jumper MM, kabel data, breadboard, sensor cahaya, dan sensor suhu.

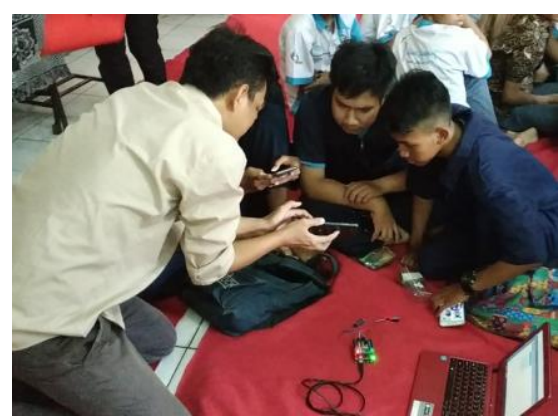

GAMBAR 3. Implementasi Iot

Kegiatan pelatihan berlangsung selama 5 jam dengan materi pelatihan monitoring dengan menggunakan sensor cahaya dan suhu dengan perangkat ardiuno. Di akhir kegiatan dilakukan pengambilan respon dengan melaksanakan postest, pembagain doorprize bagi tiga siswa terbaik pada sesi pretest dan postest, dan penyerahan pin kepada siswa yang telah mengisi form evaluasi pelaksanan pelatihan. Guru mata pelajaran meminta agar selanjutnya diadakan kegiatan seperti ini karena dirasa sangat bermanfaat bagi tambahan pengetahuan siswa-siswanya. Terakhir dilakukan foto bersama dengan siswa dan perangkat arduinonya, guru mata pelajaran dan mahasiswa.

Hasil pelatihan ini berupa data hasil pretest dan postest. Data diolah dengan menggunakan analisis statistik dengan batuan aplikasi SPSS dan Microsoft Exel. Analisis statistik terdiri dari tiga tahap yaitu analisis normalitas, homogenitas, dan uji hipotesis. Berdasarkan analisis normalitas dan homogenitas diperoleh bahwa data pretest dan data postest merupakan data sampel yang terdistribusi normal dan homogen.

Uji hipotesis dilakukan setelah data tersebut terdistribusi normal dan homogen. Uji hipotesis yang digunakan adalah uji z karena data lebih besar dari 30 dengan uji dua sisi. Untuk mempermudah dalam interpretasi, maka dibuat kurva normalitas dengan uji z. Kurva tersebut dapat dilihat pada Gambar 4 berikut.

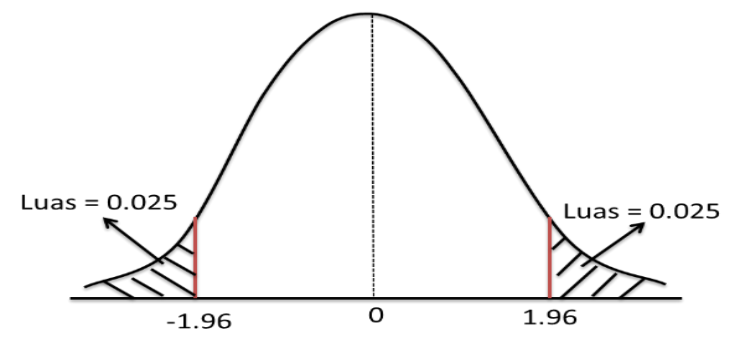

GAMBAR 4. Kurva Uji Z

Berdasarkan hasil di atas, daerah penerimaan Ho berada berada di antara -1.96 sampai dengan +1.96. Nilai z hitung -8.115 berada di luar daerah penerimaan Ho, maka Ho di tolak dan Ha diterima. Dengan demikian, uji z ini menunjukkan bahwa "Ada perbedaan antara nilai rata-rata kompetensi keahlian siswa sebelum dilakukan pelatihan dengan nilai rata-rata kompetensi keahlian siswa sesudah dilakukan pelatihan".

\section{KESIMPULAN}

Berdasarkan hasil dan pembahasan kegiatan pelatihan IoT dapat diuraikan kesimpulan bahwa kompetensi keahlian siswa dapat ditingkatkan secara signifikan melalui pelatihan IoT. Hal ini ditunjukkan berdasarkan analisis uji z yang menyatakan bahwa hipotesis: "kompetensi keahlian siswa dapat ditingkatkan secara signifikan melalui Pelatihan IoT" dapat diterima pada tingkat signifikansi 0.05. Dengan kata lain, tingkat keyakinan sebesar $95 \%$ menyatakan bahwa kompetensi 
keahlian siswa dapat ditingkatkan secara signifikan melalui pelatihan IoT. Metode pelaksanaan yang dilakukan pada pelatihan IoT adalah pelatihan berbentuk kerja kelompok yang mampu membuat pelatihan berlangsung secara efektif dan efisien.

\section{UCAPAN TERIMAKASIH}

Terimakasih kepada LPPM Universitas Binawan sebagai lembaga pemberi dana pelatihan dan Sekolah SMA Jakarta 1 yang telah memberi dukungan serta kontribusi sehingga pelatihan berjalan dengan baik dan lancar, dan semua pihak yang telah membantu penyelesaian penelitian pada pelatihan ini.

\section{REFERENSI}

Aditya, F. G. (2015). Analisis Dan Perancangan Prototype Smart Home Dengan Sistem Client Server Berbasis Platform Android Melalui Komunikasi Wireless. e-Proceeding of Engineering, 2(2). 3070-3077.

Afrizal, M. A., (2018). Rancang Bangun Rumah Pintar Berbasis IoT (Internet of Things) sebagai Media Pembelajaran pada Mata Pelajaran Pemrograman, Mikroprosesor, dan Mikrokontroller di SMKN 2 Surabaya. Jurnal Pendidikan Teknik Elektro, 7(1): 79-86.

Efendi, Y., (2018). Internet of Things (IoT) Sistem Pengendalian Lampu Menggunakan Raspberry PI Berbasis Mobile. Jurnal Ilmiah Ilmu Komputer, 4(1): 19-26.

Herfiansyah, D. A. (2014). Pembangunan Electrical Control System Berbasis Smartphone Android dengan Media Internet (Implementasi Sistem Smart Home). Jurnal Penelitian Teknik Informatika, 1 .

Junaidi, A., (2015). Internet of Things, Sejarah, Teknologi dan Penerapannya: Review. Jurnal Ilmiah Teknologi Informasi Terapan, 1(3): 62-66.

Maulana, A. (2014). Perancangan Sistem Pengukuran Warna Tanah Dengan Metode Teaching dan Running. Diploma thesis. Universitas Komputer Indonesia.

Prihatmoko, D. (2016). Penerapan Internet of Things (IoT) dalam Pembelajaran di UNISNU Jepara. Jurnal SIMETRIS, 7(2): 567-574.

Santyadiputra, G. S, Putrama, I. M, \& Sindu, I. G. P. (2017). Pelatihan Internet of Things (IoT) Untuk Pelajar Tingkat SMK Di Kecamatan Buleleng. Jurnal Seminar Nasional Vokasi dan Teknologi, 1 . 